\title{
Receptor-Type Tyrosine-Protein Phosphatase-Like N
}

National Cancer Institute

\section{Source}

National Cancer Institute. Receptor-Type Tyrosine-Protein Phosphatase-Like N. NCI

Thesaurus. Code C148308.

Receptor-Type Tyrosine-Protein Phosphatase-Like N (979 aa, $106 \mathrm{kDa}$ ) is encoded by the human PTPRN gene. This protein is involved in neurotransmitter and hormone secretion. 